\title{
KAJIAN INDEKS MODAL MANUSIA DAN PERANANNYA DALAM PERTUMBUHAN EKONOMI INDONESIA 2015-
} 2018

STUDY OF HUMAN CAPITAL INDEX AND ITS ROLE IN INDONESIAN ECONOMIC GROWTH 2015-2018

\author{
M. Nata Kesuma ${ }^{1}$, Erni Tri Astuti ${ }^{2}$ \\ Politeknik Statistika STIS ${ }^{1}$ \\ Politeknik Statistika STIS ${ }^{2}$ \\ Jalan swadaya 2 RT 3 RW 1 Pekanbaru, Riau \\ E-mail: 16.9248@stis.ac.id
}

\begin{abstract}
ABSTRAK
Pada tahun 2018, Grup Bank Dunia menjalankan sebuah projek mengenai modal manusia dan mengeluarkan sebuah indeks yakni Indeks Modal Manusia (IMM). Indeks ini akan mengukur kontribusi kesehatan dan pendidikan untuk produktivitas generasi pekerja berikutya. Badan Pusat Statistik (BPS) selaku penyelenggara statistik dasar hingga saat ini belum menghitung Indeks Modal Manusia. Padahal indeks ini dapat dijadikan acuan atau dasar bagi pemerintah dalam membuat kebijakan untuk meningkatkan pertumbuhan ekonomi. Indonesia mengalami pertumbuhan ekonomi yang stagnansi yakni $4 \%-5 \%$ dalam kurun waktu 2015-2018. Padahal pada periode sebelum tahun 2015, pertumbuhan ekonomi Indonesia mampu mencapai $6 \%$. Dalam teori pertumbuhan ekonomi neoklasik terdapat 3 faktor dalam pertumbuhan ekonomi yakni akumulasi modal, pertumbuhan penduduk yang diikuti dengan kualitasnya dan perkembangan teknologi. Penelitian ini bertujuan untuk menghitung nilai Indeks Modal Manusia Indonesia dan melihat pengaruhnya bersama Pembentukan Modal Tetap Bruto (PMTB) serta didukung oleh pengaruh teknologi yang dilihat dari nilai Indeks Pembangunan Teknologi Informasi dan Komunikasi (IP-TIK) terhadap pertumbuhan ekonomi di Indonesia pada periode 2015 hingga 2018. Metode regresi yang digunakan adalah regresi data panel. Hasilnya pada tahun 2015 hingga 2018, secara umum terjadi penurunan nilai Indeks Modal Manusia Indonesia. Sementara, pada tingkat signifikansi 5 persen PMTB dan IP-TIK berpengaruh positif dan signifikan terhadap Pertumbuhan Ekonomi. Sedangkan IMM tidak dapat menunjukkan pengaruh yang positif dan signifikan terhadap pertumbuhan ekonomi. Dari hasil tersebut, diharapkan pemerintah dapat meningkatkan PMTB dan dukungan akan kemajuan teknologi guna mendorong perekonomian.
\end{abstract}

Kata kunci: IP-TIK,IMM,PMTB,Pertumbuhan Ekonomi, Panel

\section{ABSTRACT}

In 2018, the World Bank Group ran a project on human capital and issued an index, the Human Capital Index (HCI). This index will measure the contribution of health and education to the productivity of the next generation of workers. The Central Bureau of Statistics (BPS) as the organizer of basic statistics has yet to calculate the Human Capital Index. In fact, this index can be used as a reference or basis for the government in making policies to increase economic growth. Indonesia experienced stagnant economic growth, namely $4 \%-5 \%$ in the $2015-2018$ period. Whereas in the period before 2015 , Indonesia's economic growth was able to reach $6 \%$. In the theory of neoclassical economic growth, there are 3 factors in economic growth, namely capital accumulation, population growth followed by quality and technological developments. This study aims to calculate the value of the Indonesian Human Capital Index and see its effect with the Gross Fixed Capital Formation (PMTB) and is supported by the influence of technology seen from the value of the Information and Communication Technology Development Index (ICT-Index) on economic growth in Indonesia in the 2015 to 2015 period. 2018. The regression method used is panel data regression. As a result, from 2015 to 2018, in general there was a decline in the value of the Indonesian Human Capital Index. Meanwhile, at the 5 percent significance level PMTB and IP-TIK have a positive and significant effect on economic growth. Meanwhile, IMM cannot show a positive and significant impact on economic growth. From these results, it is hoped that the government can increase PMTB and support technological advances in order to boost the economy.

Keywords: ICT-Index,HCI,PMTB,Economic Growth,Panel 


\section{PENDAHULUAN (Tahoma 12, Bold, Text Left)}

Modal Manusia merupakan salah satu komponen penting bagi perekonomian suatu negara. Manusia yang berkualitas dapat mendorong perekonomian disuatu wilayah agar lebih baik lagi. Pada tahun 2017, Grup Bank Dunia menjakankan sebuah project yang disebut Human Capital Project. Proyek ini diharapkan dapat membantu menciptakan ruang politik bagi para pemimpin nasional untuk memprioritaskan investasi modal manusia transformasional. Kemudian pada tahun 2018 dalam Konferensi Tingkat Tinggi IMF-Bank Dunia yang diselenggarakan di Bali Indonesia memperkenalkan sebuah indikator yang dapat mengukur kualitas manusia yakni Human Capital Index (HCI) atau Indeks Modal Manusia (IMM). Indeks ini dapat digunakan untuk melihat kontribusi pendidikan dan kesehatan untuk produktivitas generasi pekerja berikutnya. Badan Pusat Statistik (BPS) hingga saat ini belum menghitung IMM. BPS hanya menghitung nilai Indeks Pembangunan Manusia (IPM). Perbedaan antara IPM dan IMM adalah Indeks Modal Manusia (IMM) mampu mengukur Learning Experience sehingga dapat melihat dari segi kualitas pendidikan di suatu wilayah. IMM dapat dijadikan salah satu indikator yang dapat digunakan untuk evaluasi pembangunan manusia sehingga diharapkan mampu meningkatkan investasi yang lebih banyak pada modal manusia untuk pemerataan dan pertumbuhan ekonomi yang lebih besar.

Pertumbuhan ekonomi sendiri saat ini merupakan salah satu tolak ukur keberhasilan suatu pemerintahan memajukan negaranya. Menurut Mankiw (2003), produk domestik bruto (PDB) adalah ukuran kinerja terbaik dalam menilai perekonomian dikarenakan produk domestik bruto mampu menghitung seluruh output barang dan jasa yang dihasilkan di dalam perekonomian. Selain itu, Menurut Sukirno (2006), indikator suatu negara dapat tumbuh perekonomiannya dapat diukur dari perkembangan pendapatan riil yang dicapai oleh negara tersebut. Untuk mencapai pertumbuhan ekonomi yang baik, maka pemerintah di suatu negara harus melakukan pembangunan yang mendukung jalannya ekonomi. Dengan pembangunan yang tepat sasaran dibidang ekonomi, maka bisa mempercepat pertumbuhan ekonomi tersebut. Pembangunan pada modal fisik, modal manusia serta dibantu dengan kemajuan dan kemudahan dalam akses teknologi merupakan hal yang fundamental dan dapat dilakukan oleh pemerintah. Hal ini juga sesuai dengan teori pertumbuhan ekonomi neoklasik yang mengatakan bahwa terdapat 3 faktor pertumbuhan ekonomi yakni akumulasi modal kemudian penduduk yang diikuti oleh kualitasnya yang akan menjadi modal manusia serta kemajuan teknologi.

Pertumbuhan Ekonomi Indonesia dalam periode 2015-2018 mengalami pertumbuhan yang stagnansi. Berdasarkan data Badan Pusat Statistik, pertumbuhan ekonomi Indoensia pada periode tersebut berkisar 4\%-5\%. Padahal pada periode sebelum tahun 2015, pertumbuhan ekonomi Indonesia mampu mencapai $6 \%$.

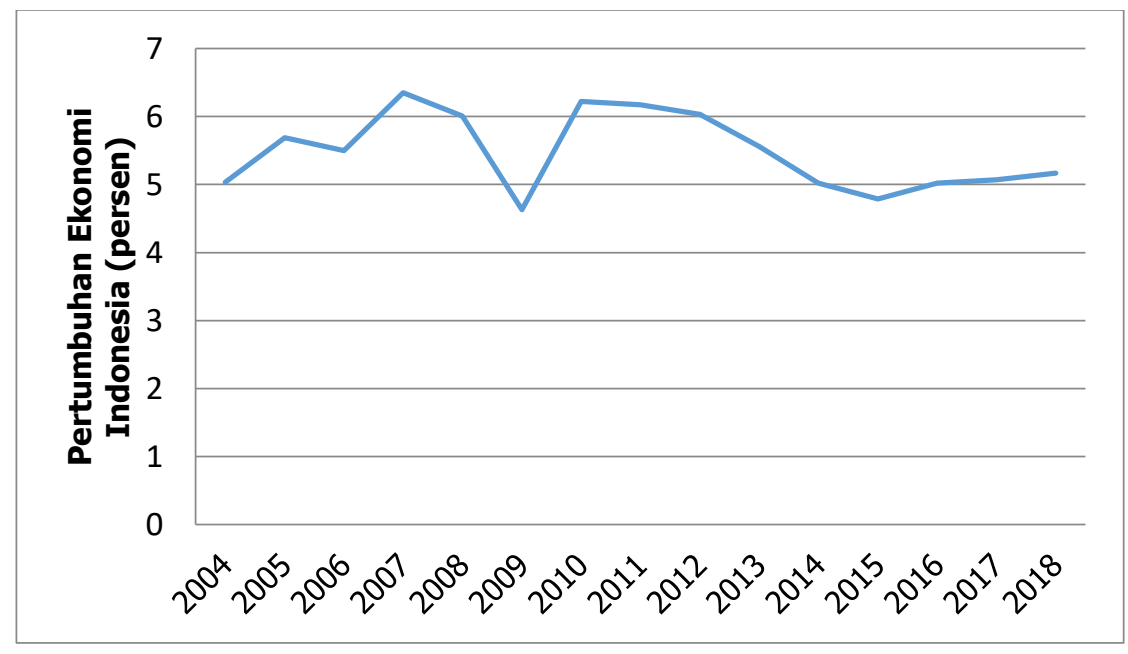

Oleh karena itu perlu adanya peningkatan pertumbuhan ekonomi di Indonesia untuk meningkatkan kesejahteraan masyarakat Indonesia. Tiga faktor pertumbuhan ekonomi tersebut yang pertama adalah akumulasi modal yakni dengan pembangunan infrastruktur. Pembangunan 
infrastruktur yang mendukung kebijakan, $\mathrm{Hal}$ ini senada dengan yang telah disampaikan oleh Todaro (2000) dimana tingkat ketersediaan infrastruktur disuatu negara merupakan faktor penting dan penentu bagi tingkat kecepatan dan perluasan pembangunan ekonomi. Untuk melakukan pembangunan infrastruktur tersebut diperlukan dana atau investasi dalam melakukannya. Menurut teori ekonomi Sollow Swan Negara Negara yang menabung dan menginvestasikan sebagian besar output akan lebih kaya daripada Negara yang menabung dan menginvestasikan sedikit output. Oleh karena itu perlu adanya investasi di suatu Negara agar dapat meningkatkan akumulasi modal negara tersebut. Pembentukan Modal Tetap Bruto (PMTB) bisa menjadi salah satu indikator untuk melihat investasi dan ketersediaan modal di suatu wilayah. Pembentukan Modal Tetap Bruto (PMTB) adalah pengeluaran untuk barang modal yang mempunyai umur pemakaian lebih dari satu tahun dan tidak merupakan barang konsumsi. PMTB mencakup bangunan tempat tinggal dan bukan tempat tinggal, bangunan lain seperti jalan dan bandara, serta mesin dan peralatan (Badan Pusat Statistik).

Kemudian yang kedua adalah penduduk yang diikuti kualitasnya atau pembangunan pada sumber daya manusia. Pembangunan pada sumber daya manusia ini merupakan salah satu hal yang menjadi perhatian khusus bagi negara-negara di dunia. Hal ini dikarenakan modal manusia menjadi salah satu faktor penting yang bisa mendongkrak perekonomian. Dan juga menurut Grup Bank Dunia (2018), tanpa modal manusia, negara-negara tidak dapat mempertahankan pertumbuhan ekonomi, tidak akan memiliki tenaga kerja yang dipersiapkan untuk pekerjaan yang lebih terampil di masa depan, dan tidak akan bisa bersaing secara efektif dalam ekonomi global. Becker dalam Abbas (2010) menunjukkan bahwa modal manusia mampu menjawab penyebab negara-negara yang miskin atau memiliki sedikit sumber daya alam mampu menjadi negara maju dan mencapai pertumbuhan ekonomi yang cepat dibandingkan dengan negara negara yang kaya sumber daya alam. Hal ini dikarenakan negara-negara tersebut telah melakukan investasi besarbesaran dalam modal manusia. World Bank Group pada proyek modal manusia (2017) beranggapan bahwa kita dapat mengakhiri kemiskinan ekstrem dan menciptakan masyarakat yang inklusif dengan mengembangkan modal manusia. Hal ini membutuhkan investasi pada orangorang melalui nutrisi, perawatan kesehatan, pendidikan berkualitas, pekerjaan dan keterampilan. Pada tahun 2018, grup bank dunia telah mengeluarkan suatu indeks yakni Iindeks Modal Manusia yang mengukur mengenai modal manusia, dan bisa digunakan untuk melihat kontribusi pendidikan dan kesehatan untuk produktivitas generasi pekerja berikutnya. Hal ini bisa menjadi salah satu acuan kebijakan, sehingga pemerintah dapat membuat kebijakan yang tepat sasaran, sehingga mampu meningkatkan produktivitas pekerja pada generasi pekerja berikutnya dan mendorong perekonomian.

Selanjutnya yang ketiga adalah kemajuan teknologi. peran dari kemajuan teknologi pada saat ini juga banyak mempengaruhi perekonomian disuatu Negara. Kemajuan teknologi bagi kebanyakan ekonom merupakan sumber pertumbuhan ekonomi yang paling penting (Todaro \& Smith 2004). Menurut Tan Wee Kwang (2015) teknologi informasi dan komunikasi sangat penting bagi perkembangan ekonomi negara-negara berkembang dan maju. Pada tahun 2016, data World Bank memperkirakan TIK menyumbang 17 persen petumbuhan Produk Domestik Bruto (PDB) di negara-negara berkembang. Salah satu ukuran standar untuk melihat gambaran tingkat pembangunan teknologi informasi dan komunikasi suatu wilayah, kesenjangan digital, serta potensi pengembangan TIK dapat dilihat melalui nilai Indeks Pembangunan Teknologi Informasi dan Komunikasi (IP-TIK). Dengan ketiga faktor tersebut diharapkan mampu berpengaruh terhadap perekonomian di Indonesia.

Penelitian mengenai pengaruh Modal Manusia,PMTB dan IP-TIK terhadap pertumbuhan ekonomi telah dilakukan sebelumnya. Penelitian yang dilakukan oleh Amri \& Aimon (2017) mengenai pengaruh pembentukan modal dan ekspor tehradap pertumbuhan ekonomi Indonesia, ditemukan bahwa PMTB berpengaruh pada pertumbuhan ekonomi baik dijangka pendek maupun jangka panjang. Penelitian tersebut menggunakan Vector Error Correction Model (VECM) dalam penelitiannya. Kemudian penelitian yang dilakukan oleh Jowanti \& Utami (2017) mengenai pengaruh perdagangan internasional, FDI, Pasar Modal, dan PMTB terhadap perekonomian di Negara ASEAN-5 tahun 2000-2015 menemukan bahwa PMTB berpengaruh positif terhadap perekonomian. Penelitian tersebut menggunakan regresi data panel dalam penelitiannya. 
Penelitian selanjutnya yang dilakukan oleh Pelinescu (2014) yang berjudul the impact of human capital on economic growth yang dilakukan di eropa menemukan bahwa dengan alpha $10 \%$ dan dengan variabel number of employees with secondary education, export of goods dan services dan the number of patent berpengaruh secara positif dan signifikan terhadap pertumbuhan ekonomi. Sedangkan variable education expenditure berpengaruh secara negative dan siginikan terhadap pertumbuhan ekonomi. Penelitian tersebut menggunakan regresi data panel dalam menganalisis variable variable dalam penenlitiannya. Kemudian penelitian yang dilakukan oleh nurhayati dan suparman (2015) mengenai analisis pengaruh modal manusia terhadap pertumbuhan ekonomi di provinsi jawa timur tahun 2012, ditemukan bahwa populasi (jumlah penduduk) dan pendidikan yakni Indeks Kemampuan baca tulis dan indeks masa sekolah bruto berpengaruh secaa positif dan signifikan terhadap Pertumbuhan ekonom. Sedangkan untuk variable kesehatan yakni ketersediaan tenaga medis + sarana prasarana kesehatan) memiliki pengaruh negative dan signifikan terhadap Pertumbuhan ekonomi. Selanjutnya penelitian mengenai pengaruh teknologi terhadap pertumbuhan ekonomi yang berjudul ICT \& Economic growth : A Comparison Between Developed and Developing Countries yang dilakukan oleh samimi dkk pada tahun 2015, menunjukkan bahwa ICT lebih berpengaruh di Negara sedang berkembang dibanding Negara maju. Penelitian tersebut menggunakan regresi data panel untuk metode penelitiannya.Kemudian penelitian lainnya yang dilakukan oleh Aghaei dan Rezagholizadeh tahun 2017 yang berjudul The Impact of Information Communication Technology (ICT) on Economic growth yang dilakukan pada Negara Negara OIC, menunjukkan bahwa ICT berpengaruh pada perekonomian, baik dari sisi penawaran ataupun permintaan. Pada sisi penawaran, ICT berpengaruh terhadap fungsi produksi, sedangkan pada sisi permintaan, ICT berpengaruh pada fungsi kepuasan. Pada penelitiannya, metode yang digunakan adalah metode regresi data panel.

Berdasarkan uraian diatas, maka tujuan penelitian kali ini adalah perhitungan nilai Indeks Modal Manusia Indonesia hingga level provinsi. Kemudian memodelkan faktor faktor pertumbuhan ekonomi berdasarkan teori pertumbuhan ekonomi neoklasik dan melihat pengaruh dari setiap faktor tersebut terhadap perekonomian di Indonesia.

\section{METODE}

Penelitian ini mencakup 33 provinsi di Indonesia. Provinsi Kalimantan Utara yang baru mekar pada tahun 2012 di masukkan kedalam provinsi induk yakni Provinsi Kalimantan Timur. Hal ini dikarenakan masih banyaknya data yang belum tersedia untuk provinsi Kalimantan Utara. Periode penelitian yang digunakan adalah tahun 2015-2018. Variable Dependen pada penelitian ini adalah Produk Domestik Regional Bruto (PDRB) per Kapita sedangkan untuk variabel Independen adalah Indeks Modal Manusia yang nantinya akan dihitung terlebih dahulu disetiap Provinsi sesuai dengan perhitungan yang telah dilakukan oleh grup bank dunia. Kemudian Pembentukan Modal Tetap Bruto dan Indeks Pembangunan Teknologi Informasi dan Komunikasi akan menjadi variabel Independen Tambahan dalam penelitian kali ini.

Indeks Modal Manusia dibentuk dari 3 komponen dan 5 indikator. Pertama Ketahanan anak yang terdiri dari 1 indikator, yakni peluang hidup hingga usia 5 tahun. Indikator ini dihitung dari ratio antara kematian pada usia kurang dari lima tahun dan jumlah penduduk yang berusia kurang dari lima tahun. Berikut rumus perhitungan komponen ini :

$$
\text { Peluang bertahan hidup } 0-4=1-\frac{\text { jumlah kematian umur } 0-4 \text { tahun }}{\text { jumlah penduduk umur } 0-4 \text { tahun }}
$$

Komponen kedua adalah Pendidikan yang terdiri dari dua indikator yakni nilai dari harapan lama sekolah dan harmonized test scores. Harmonized test scores adalah nilai yang didapat dari suatu test yang dilakukan oleh grup bank dunia pada warga negara indonesia yang bekerja di world bank serta penyelarasan nilai ujian dari program pengujian prestasi siswa internasional utama. Berikut adalah rumus perhitungan untuk komponen pendidikan :

$$
\operatorname{Exp}\left(0,08 x \frac{(\text { Harmonized Test Score } x \text { Lama Sekolah })}{(625-16)}\right.
$$


Kemudian untuk komponen terakhir adalah komponen kesehatan yang terdiri dari dua indikator yakni angka tidak stunting pada usia kurang dari lima tahun dan peluang ketahanan hidup manusia yang berusia 15-60 tahun. Berikut adalah rumus yang digunakan :

Jika jumlah angka tidak stunting dan Peluang bertahan hidup berusia 15-60 tahun adalah 2, maka menggunakan rumus :

$$
\sqrt{\exp ((0,034 \times 10,2 \times(\text { Tidak stunting }-1))+(0,034 \times 19,2 \times \text { Prob }-1)}
$$

Jika jumlah angka tidak stunting dan peluang bertahan hidup berusia 15-60 tahun kurang dari 2, maka menggunakan rumus :

$$
\exp ((0,034 \times 10,2 \times(\text { Tidak stunting }-1))+(0,034 \times 19,2 \times \text { Prob }-1) \ldots
$$

Setalah mendapatkan nilai dari setiap komponen, rumus perhitungan indeks modal manusia sangat sederhana, yakni setiap komponen dikali dengan komponen lainnya dan nilai akhir dari nilai indeks ini adalah rentang nilai 0-1. Nantinya nilai dari indeks modal manusia diinterpretasikan sebagai kesempatan seorang anak yang lahir untuk dapat tumbuh, dengan catatan mereka menyelesaikan pendidikan dan mendapat akses kesehatan yang baik. Rumus perhitugan Indeks Modal Manusia dapat dituliskan sebagai berikut :

$$
\text { Indeks Modal Manusia = Ketahanan Anak } x \text { Pendidikan } x \text { Kesehatan....... }
$$

Selanjutnya, setelah memperoleh nilai Indeks Modal Manusia, akan dilihat pengaruh indeks tersebut bersama Pembentukan Modal Tetap Bruto dan IP-TIK terhadap pertumbuhan ekonomi. Analisis akan dilakukan dengan metode regresi data panel dan menggunakan metode estimasi weight least square. Berikut persamaan yang digunakan pada penelitian ini :

$$
Y_{i t}=\left(\alpha+\mu_{i}\right)+\beta_{1} X_{1 i t}+\beta_{2} X_{2 i t}+\beta_{3} X_{3 i t}+v_{i t}
$$

Keterangan :

$Y_{i t}:$ PDRB Perkapita

$\left(\alpha+\mu_{i}\right)=\alpha_{i}=$ Intersep Propinsi ke $i(i=1, \ldots, 33)$

$X_{1}=P M T B$

$X_{2}=H C I$

$X_{3}=I P-T I K$

$\beta_{j}=$ parameter model $(j=1,2,3)$

$v_{i t}=$ error provinsi ke i periode ke $\mathrm{t}$

$\mathrm{i}=$ Provinsi

$\mathrm{t}=$ Tahun

\section{HASIL DAN PEMBAHASAN}

Berdasarkan perhitungan nilai Indeks Modal Manusia di 33 provinsi di Indonesia, diperoleh hasil bahwasanya terjadi penurunan nilai Indeks Modal Manusia Indonesia dari taun 2015-2018. Pada tahun 2015, nilai Indeks Modal Manusia adalah 0,57 yang berarti setiap anak yang lahir memiliki kesempatan 57\% untuk dapat tumbuh dengan catatan mereka menyelesaikan pendidikan dan mendapatkan kesehatan yang baik. Kemudian pada tahun 2016 hingga tahun 2018 terjadi trend penurunan sebesar 0,1 sehingga nilai Indeks Modal Manusia dalam kurun waktu tersebut secara berturut-turut adalah 0,56;0,55, ; dan 0,54. Sementara, untuk level provinsi, selama periode penelitian, provinsi Yogyakarta menjadi provinsi dengan nilai IMM tertinggi. Nilai Indeks Modal Manusia provinsi Yogyakarta berturut-turut adalah 0,$69 ; 0,69 ; 0,69$; dan 0,70. Hal itu menunjukkan bahwasanya setiap anak yang lahir memiliki kesempatan 69\%-70\% untuk dapat tumbuh dengan catatan mereka menyelesaikan pendidikan dan mendapatkan akses kesehatan yang baik. Sementara provinsi Papua menjadi provinsi dengan nilai IMM selama periode penelitian dengan nilai berturut-turut sebesar 0,$47 ; 0,47 ; 0,46 ;$ dan 0,47 . Hal itu menunjukkan di provinsi Papua setiap anak yang lahir memiliki kesempatan $46 \%-47 \%$ untuk dapat tumbuh dengan catatan mereka menyelesaikan pendidikan dan mendapat akses kesehatan yang baik. 
Tabel 1. Indeks Modal Manusia pada level Provinsi

\begin{tabular}{|l|r|r|r|r|}
\hline \multirow{2}{*}{ Provinsi } & \multicolumn{4}{|c|}{ Indeks Modal Manusia } \\
\cline { 2 - 5 } & 2015 & 2016 & 2017 & 2018 \\
\hline ACEH & 0.61 & 0.59 & 0.56 & 0.54 \\
\hline SUMATERA UTARA & 0.59 & 0.60 & 0.57 & 0.53 \\
\hline SUMATERA BARAT & 0.60 & 0.58 & 0.57 & 0.58 \\
\hline RIAU & 0.59 & 0.58 & 0.55 & 0.54 \\
\hline JAMBI & 0.56 & 0.55 & 0.54 & 0.53 \\
\hline SUMATERA SELATAN & 0.56 & 0.54 & 0.53 & 0.50 \\
\hline BENGKULU & 0.57 & 0.56 & 0.55 & 0.55 \\
\hline LAMPUNG & 0.54 & 0.54 & 0.52 & 0.52 \\
\hline KEP. BANGKA BELITUNG & 0.52 & 0.52 & 0.51 & 0.52 \\
\hline KEP. RIAU & 0.56 & 0.56 & 0.56 & 0.56 \\
\hline DKI JAKARTA & 0.61 & 0.58 & 0.57 & 0.58 \\
\hline JAWA BARAT & 0.54 & 0.56 & 0.55 & 0.53 \\
\hline JAWA TENGAH & 0.55 & 0.55 & 0.54 & 0.53 \\
\hline DI YOGYAKARTA & 0.69 & 0.69 & 0.69 & 0.70 \\
\hline JAWA TIMUR & 0.58 & 0.58 & 0.56 & 0.54 \\
\hline BANTEN & 0.54 & 0.53 & 0.52 & 0.53 \\
\hline BALI & 0.60 & 0.58 & 0.57 & 0.57 \\
\hline NUSA TENGGARA BARAT & 0.56 & 0.55 & 0.54 & 0.53 \\
\hline NUSA TENGGARA TIMUR & 0.53 & 0.53 & 0.53 & 0.52 \\
\hline KALIMANTAN BARAT & 0.53 & 0.52 & 0.51 & 0.51 \\
\hline KALIMANTAN TENGAH & 0.54 & 0.53 & 0.52 & 0.52 \\
\hline KALIMANTAN SELATAN & 0.54 & 0.54 & 0.52 & 0.52 \\
\hline KALIMANTAN TIMUR & 0.57 & 0.58 & 0.56 & 0.57 \\
\hline SULAWESI UTARA & 0.59 & 0.57 & 0.54 & 0.53 \\
\hline SULAWESI TENGAH & 0.55 & 0.55 & 0.53 & 0.53 \\
\hline SULAWESI SELATAN & 0.58 & 0.56 & 0.55 & 0.53 \\
\hline SULAWESI TENGGARA & 0.58 & 0.57 & 0.56 & 0.56 \\
\hline GORONTALO & 0.56 & 0.54 & 0.54 & 0.52 \\
\hline SULAWESI BARAT & 0.53 & 0.50 & 0.50 & 0.49 \\
\hline MALUKU & 0.60 & 0.59 & 0.59 & 0.58 \\
\hline MALUKU UTARA & 0.60 & 0.60 & 0.58 & 0.57 \\
\hline PAPUA BARAT & 0.55 & 0.55 & 0.54 & 0.54 \\
\hline PAPUA & 0.47 & 0.47 & 0.46 & 0.47 \\
\hline INDONESIA & 0.57 & 0.56 & 0.55 & 0.54 \\
\hline
\end{tabular}

Selanjutnya, berdasarkan data empiris yang diperoleh dari Badan Pusat Statistik (BPS) dan Kementerian Pendidikan dan Kebudayaan (KEMENDIKBUD) dan pengujian dengan menggunakan analisis regresi data panel dengan metode estimasi Weight Least Square, diperoleh hasil bahwasanya dengan tingkat signifikansi sebesar 5\% IMM,PMTB, dan IP-TIK secara bersama-sama berpengaruh terhadap pertumbuhan ekonomi di Indonesia (Tabel 1). Sedangkan secara parsial, PEMBENTUKAN Modal Tetap Bruto (PMTB) mampu menunjukkan pengaruh yang positif dan signifikan terhadap pertumbuhan ekonomi di Indonesia. Hal ini menunjukkan pengaruh adanya pengaruh yang positif dari investasi yang dilakukan pemerintah terutama dibidang infrastruktur terhadap perekonomian di Indonesia. Hal yang sama juga terjadi pada variabel Indeks Pembangunan Teknologi Informasi dan Komunikasi (IP-TIK) yang juga memberikan dampak yang positif dan signifikan terhadap perekonomian di Indonesia. Hal ini menunjukkan kemajuan teknologi saat ini memberikan dampak yang baik bagi perekonomian di Indonesia. Sementara itu, hal yang berbeda ditunjukkan variabe Indeks Modal Manusia (IMM) yang belum mampu menunjukkan pengaruh yang positif dan signifikan terhadap perekonomian di Indonesia.

Tabel 2. Hasil Pengolahan Regresi Data Panel

\begin{tabular}{|c|c|c|c|c|}
\hline Variable & $(\widehat{\boldsymbol{\beta}})$ & S.E $(\widehat{\boldsymbol{\beta}})$ & t-Statistics & p-value \\
\hline Konstanta & 38133.20 & 3977.959 & 9.586121 & 0.0000 \\
\hline
\end{tabular}




\begin{tabular}{|c|c|c|c|c|}
\hline PMTB & 0.000807 & 0.000133 & 6.049440 & 0.0000 \\
\hline IMM & -20592.48 & 5824.939 & -3.535227 & 0.9999 \\
\hline IP-TIK & 936.2829 & 145.5549 & 6.432507 & 0.0000 \\
\hline \multicolumn{5}{|c|}{ Ringkasan Statistik } \\
\hline R-Square & 0.999167 & F-Statistics & 3291.424 & \\
\hline Adjusted $R$-Square & 0.998864 & Prob (F-statistics) & 0.0000 & \\
\hline
\end{tabular}

Dari hasil estimasi, dapat dituliskan model persamaan penelitian sebagai berikut :

$$
\widehat{P D R B}_{\text {it }}=38133.20+0.000807 \text { (PMTB)* } 20592.48 \text { (IMM) + 936.2829(IP-TIK)* }
$$

Sementara untuk efek individu, provinsi tertinggi adalah provinsi Kalimantan Timur dengan nilai sebesar 76820.45, sedangkan untuk yang terendah berada di provinsi Jawa Barat dengan nilai sebesar -30178.90. efek individu menggambarkan rata-rata nilai PDRB perkapita disaat variabel independennya dianggap konstan

\section{KESIMPULAN}

Berdasarkan hasil penelitian, dapat disimpulkan bahwa selama periode penelitian terjadi penurunan nilai indeks modal manusia Indonesia. Sementara untuk level provinsi, provinsi Yogyakarta menjadi provinsi dengan nilai indeks modal manusia tertinggi selama periode penelitian. Sementara untuk nilai indeks terendah, selama periode 2015-2018 berada di provinsi Papua. Selanjutnya setelah memperoleh nilai indeks modal manusia di setiap provinsi, nilai indeks tersebut akan dilihat pengaruhnya bersama PMTB dan IP-TIK terhadap perekonomian Indonesia. Analisis dilakukan dengan regresi data panel dan diperoleh hasil dengan tingkat signifikansi $5 \%$ PMTB dan IP-TIK mampu menunjukkan pengaruh yang positif dan signifikan terhadap perekonomian di Indonesia. Sementara itu Indeks Modal Manusia sendiri belum mampu menunjukkan pengaruh yang positif dan signifikan terhadap perekonomian Indonesia. Dari hasil tersebut diharapkan pemerintah untuk terus meningkatkan investasi utamanya untuk infrastruktur infrastruktur umum dan juga mendukung kemajuan teknologi dengan mendukung dan menambah fasilitas yang mampu meningkatkan perkembangan teknologi di Indonesia guna meningkatkan dan mendorong perekonomian indonesia agar lebih baik lagi.

\section{DAFTAR PUSTAKA}

Aghei, Majid dan Mahdieh Rezagholizadeh .(2017). The Impact of Information and Communication Technology (ICT) on Economic Growth in the OIC Ciuntries ISSN paper version 1642-2597

Amri, K \& Aimon, H. (2017). PengaruhPembentukan Modal dan Ekspor terhadap Pertumbuhan Ekonomi Indonesia. Economac Volume 1 issue april 2017 e-ISSN 2549-9807

BPS, (2018). Berita Resmi Statistik Perkembangan Indeks Pembangunan Teknologi Informasi dan Komunikasi (IP-TIK), Jakarta

BPS, (2018). Statistik Indonesia 2016, Jakarta

BPS, (2018). Statistik Indonesia 2017, Jakarta

BPS, (2018). Statistik Indonesia 2018, Jakarta

BPS, (2018). Statistik Indonesia 2019, Jakarta

Baltagi, H. Badi, (2005). Econometric Analysis of Data Pane/ $3^{\text {th }}$ Edition. New Delhi, India

Greene, William H. (2003). Econometric Analysis Person Education $5^{\text {th }}$ Edition. New Jersey : Prentice Hall Greene, William H. (2012). Econometric Analysis Person Education th Edition. New Jersey : Prentice Hall Gujarati, Damodar N. (2004). Basic Econometrics. $4^{\text {th }}$ Edition. Singapura : McGraw-Hill Inc. 
Gujarati, Damodar N. \& Porter, Dawn C (2009). Basic Econometrics. $5^{\text {th }}$ Edition. New York: McGraw-Hill Companies.

Kementerian Pendidikan dan Kebudayaan. (2019). Diakses pada 17 November 2019 melalui https://hasilun.puspendik.kemdikbud.go.id/\#2019!smp!capaian!99\&99\&999!T\&T\&T\&T\&1\&!1!\&

Kwang, Tan Wee. (22 Desember 2015). The Impact of ICT on the Global Eeconomy.

Mankiw, Gregory N. (2003). Teori Makroekonomi Ed-5. Jakarta: Erlangga

Pelinescu, Elena. (2014). The Impact of Human Capital on economic growth. $2^{\text {nd }}$ International Conference Economic Scientific Research-Theoretical, Emperical and Practical Approaches

Sukirno, Sadono. (2006). Makroekonomi Teori Pengantar (Edisi ke-3). Jakarta: Rajawali Press

Samimi, Ahad Jafari, Robabe Bababanejad Ledary dan Mohammad Hossein Jafari Samimi. (2015). ICT \&Economic Growth: A Comparison Between Ddeveloped \& Developing Countries. International Journal of Life Science and Engineering.

World Bank. (2018). Human Capital Project. Diakses pada 11 November 2019 melalui https://www.worldbank.org/en/publication/human-capital 